\title{
Las técnicas documentales en el proceso de aprendizaje
}

\section{María Pinto Molina}

Destacar la importancia de la Información y Documentación como disciplina auxiliar del individuo en las más variadas empresas es la tarea prioritaria del presente artículo, en el que intentaremos resaltar la función de las Técnicas Documentales ante cualquier proceso de aprendizaje.

\section{La Información y Documentación científicas}

En la sociedad actual la Información ha llegado a ser una necesidad primaria del hombre equiparable a aquellas otras impuestas por su propia biología. Y es lógico que esto haya sucedido en una cultura cientifica como la nuestra, máxime si pensamos que la razón de ser de la ciencia, producto social dinámico en permanente evolución, estriba precisamente en el flujo de conocimientos que proporciona la Información.

Por otra parte, el proceso de producción bibliográfica, cuyo crecimiento ha sido continuo y progresivo, experimentó un notable desarrollo durante el pasado siglo, cuando el libro se hizo socialmente imprescindible y las publicaciones periódicas de carácter científico aumentaban sin cesar. Como ha señalado Mijailov, ${ }^{1}$ la literatura científica se duplica cada 15 ó 20 años, obedeciendo este crecimiento a una curva exponencial. El propio Ortega y Gasset ${ }^{2}$ nos indicaba como una de las grandes dificultades del hombre de ciencia de la época estribaba en orientarse sobre una determinada bibliografía. Incluso Bernal ${ }^{3}$ llegó a asegurar que a veces era más fácil redescubrir un fenómeno que enterarse por la literatura de que tal logro había sido descubierto con anterioridad.

Por consiguiente, no es de extrañar que muchos estudiosos reclamaran, en defensa de la economía del esfuerzo mental, la creación de nuevas técnicas bibliográficas de ayuda al individuo en la denominada selva documental.

Además, la revolución cuantitativa conocida como "explosión documental" acarreó también algunos cambios de indole cualitativa, pues por un lado el libro perdió su hasta entonces incuestionable hegemonía, ante la fuerte competencia planteada por el

(1) MUAILOV, A.I.; CHERNII, A.I.; GUILIAREVSKII, R.S.: Fundamentos de infomática. La Habana, Academia de Ciencias de Cuba, 1973, T.I, p. 21 y ss.

(2) ORTEGA Y GASSET, J.: Misión de la Universidad. En: Obras Completas. Madrid, Revista de Occidente, 1957, v. IV.

(3) BERNAL, J.D.: H' social de la Ciencia. Barcelona, Peninsula, 1979, T. I, p. 43. 
"artículo de revista", de tal modo que el concepto de documento se hizo mucho más universal; y por otro, la más reciente aparición de nuevas tecnologías, en especial la informática, ha modificado los sistemas de almacenamiento y tratamiento de información.

En suma, la Información, como fenómeno sociológico de nuestro siglo, ha llegado a adquirir categoría científica, generando sus propios sistemas internos, entendiendo por tales el conjunto de operaciones que a grandes rasgos empiezan en su recogida, pasan por el tratamiento y terminan en el almacenamiento necesario para su posterior difusión.

De entre los sistemas de información existentes nos centraremos en el de la Documentación, entendida en palabras de Chaumier como "un sistema formalizado de información con vocación propia". Nacida en nuestro siglo gracias a la intuición y esfuerzo de dos abogados belgas, Otlet y La Fontaine, toma carta de naturaleza con la fundación en el año 1895 de Instituto Internacional de Bibliografía, cuyo objetivo más inmediato era la elaboración de un repertorio bibliográfico universal y el establecimiento de la cooperación internacional en todos los órdenes. Después de cambiar su denominación, se transformó en la actual Federación Internacional de Documentación (FID), año 1938. Las ideas de Otlet alcanzaron su punto culminante de madurez en 1934, con la publicación de su Tratado de Documentación ${ }^{4}$, considerado como el primer libro de estas características que se escribe en el mundo, aun con las limitaciones inherentes al marco epistemológico en que se movia, como fueron las doctrinas positivistas y evolucionistas de Compte y Spencer. El objeto propio de la Documentación sería por un lado, el documento, que es por naturaleza "instrumento acumulador y difusor de la ciencia", y como tal debe ser estudiado en todos sus aspectos; y por otro, el estar documentado.

En cualquier cado, la Documentación formará un cuerpo sistemático de conocimientos cuando se constituya como ciencia y doctrina, que estudie todos los aspectos desde los que puede ser estudiado el documento; técnica, empleando un conjunto de reglas manuales y automáticas que abarcan todo el ciclo de operaciones dirigidas a analizar, organizar y difundir la información registrada en los documentos, y organización, potenciando la cooperación internacional.

Entre las características de la Documentación debemos resaltar su alto grado de condicionamiento tecnológico, ya que se trata de una técnica contemporánea, y su interdisciplinariedad, de acuerdo con sus más primitivas metas universalistas. Pero por encima de estas circunstancias, la polifacética Documentación destaca por su vocación de intermedidaria entre el documento y el usuario, labor en la que se ha hecho imprescindible, pues hoy día es imposible concebir un proceso científico sin contar con un permanente apoyo documental.

Ya en el plano operativo debemos indicar que la Documentación como actividad específica se lleva a cabo en organismos singulares - Centros de Documentación, Servicios de Información - que, a diferencia de las Bibliotecas, ofrecen el análisis y tratamiento de la información, su eficaz recuperación, y la rápida difusión de los produc-

(4) OTLET, P.: Traité de documentation. Le livre sur le livre. Theorie a pratique. Bruxelles, Editions Mundaneum, 1934. 
tos documentales. Surge asi una nueva profesión, la de documentalista, con un prometedor mercado de trabajo que irá en aumento a medida que España se vaya integrando en la órbita de los paises desarrollados y las autoridades competentes decidan dinamizar nuestro gran patrimonio documental.

\section{Las Técnicas documentales}

En general todo proceso documental, debido a su naturaleza comunicativa, necesita para llevarse a término de estos tres ingredientes: un emisor o documentalista, que como sujeto cualificado será el encargado de aplicar las técnicas pertinentes; un mensaje, o documento en sentido amplio; y un destinatario o usuario, que será el beneficiario directo de dicho proceso al obtener con rapidez, precisión y garantía la información demandada.

Como se ha puesto de manifiesto, el documento es acumulación de información, pero dirá el profesor López Yepes ${ }^{5}$ que, "aún siendo información vehiculada, es de suyo realidad estática si no se arbitran los recursos necesarios para su oportuna potenciación en la transmisión y difusión. Para que ello tenga lugar debe agilizarse un procedimiento, un proceso documental que posibilite la dinamización de la información, guardada en el documento, por medio de su difusión, dándola a conocer de esta forma al usuario". En definitiva es en este proceso donde se desarrollan un conjunto de técnicas documentales u operaciones imprescindibles en la puesta a punto de los sistemas de información. A groso modo, las podemos agrupar en estos tres apartados: colecta, tratamiento y difusión. Si bien hay cierta unidad de criterio en el contenido de la colecta y difusión, es en la técnica del tratamiento donde surgen divisiones, pues mientras unos agrupan bajo este epigrafe el conjunto de operaciones de análisis y recuperación (López Yepes, García Gutiérrez...), otros sólo se refieren al análisis (Amat Noguera...) y algunos lo vinculan exclusivamente a la recuperación documental (Couture de Troismonts...)

La colecta englobaría las tareas de adquisición y selección. La primera es de suma importancia y trascendencia, ya que permite la constitución del fondo documental en cualquier sistema de información, y requiere al menos, el conocimiento en profundidad de los objetivos y medios de la unidad documental asi como de las necesidades actuales y previsibles de los usuarios; la puesta a punto de un método riguroso de selección de documentos, y utilización regular de instrumentos y fuentes de información para el rastreo de documentos. La selección, supone un juicio de valor respecto al interés y actualidad de los documentos en el sistema, ya que es imposible someter a tratamiento todo lo que llega.

El tratamiento documental abarca "el conjunto de operaciones efectuadas para la transformación o puesta en forma, la puesta en memoria y la restitución según las necesidades de información contenidas en los documentos recogidos". ${ }^{6}$ Comprende por

\footnotetext{
(5) LOPEZ YEPES, J.; SAGREDO FERNANDEZ, F. y otros: Estudios de Documentación general e informativa. Madrid, Seminario Millares Carlo, 1981, p. 126.

(6) CHAUMIER, J.: Techniques documentaires. Paris, PUF, 1979, p. 13.
} 
tanto dos importantes fases interrelacionadas como son el análisis y la recuperación. El análisis incluye una serie de operaciones que afectan al documento original en su integridad $\longrightarrow$ sea desde el punto de vista de su forma o soporte (análisis formal) y de su contenido (análisis interno) - transformándolos o generando otros de carácter instrumental, con el objetivo último de servicio a la comunidad científica al facilitar la identificación y localización precisa de aquéllos. Dentro del análisis formal distinguiremos la técnica de catalogación, que a grandes rasgos, puede entenderse como el proceso por el cual son transferidos, conforme a determinadas reglas ciertos datos técnicos de un documento a un soporte, para su identificación física dentro de una colección específica. El resultado será la creación de un catálogo. El análisis interno lo conforman dos técnicas importantes: de un lado, la de resumir, que mediante un proceso analítico-sintético recoge la sustancia informativa de un documento, y de otro, la de indizar, consistente en entresacar del contenido de un documento unas palabras significativas o descriptores relevantes con fines identificatorios, siendo su grado de profundidad analítica menor que en la técnica de resumir. Los productos de ambas técnicas serán respectivamente el resumen, presentado bajo la forma de revista, y el índice, concretado generalmente en un boletín.

La recuperación -es decir, el otro eje del análisis documental一, más cercano a la difusión y al output de los entes documentales, permite gracias a la utilización de una adecuada estrategia de búsqueda, la localización de los documentos almacenados en la memoria documental. Y su éxito sólo será factible si se fundamenta en una acertada y rigurosa técnica analítica.

Por último, como gran apartado del proceso documental estaría la difusion, que justifica de por si la existencia de cualquier servicio de documentación. En efecto, va orientada hacia la comunidad de usuarios, a quienes pondrá en contacto con la información deseada merced a los servicios (acceso a documentos, préstamo, búsqueda...) y productos documentales (boletín bibliográfico, difusión selectiva de la información, boletines de indices y resúmenes...)

Sin duda alguna, el alto grado de condicionamiento tecnológico -en especial electrónico e informático - va a mediatizar hoy día el desarrollo de las técnicas documentales. Sirvan de ejemplo los nuevos soprotes de almacenamiento de información (videodisco, CD ROM...), los sistemas expertos para el tratamiento de información; los nuevos medios de acceso al documento original (telefax....). En suma, Tecnología y Documentación se funden y confunden con frecuencia.

\section{EI proceso de aprendizaje}

Una de las grandes preocupaciones del docente en el ámbito universitario es la puesta en práctica de un adecuado sistema de aprendizaje, o conjunto de estrategias y habilidades que permitan al discente una racionalización de esfuerzos en el proceso de aprehensión y asmilación de conocimientos. Aprender a aprender, escribe Hein,?

(7) HEIN, E.: Leaming to leam with independent study guides. Peabdy joumal of education, april, 1978, p. 197. 
seguirá siendo la clave para una filosofía de la educación. Pero aprender no es recibir pasivamente conocimientos; hay además que asimilarlos, es decir, recrearlos y hacerlos propios. De ahí que el comportamiento del discente tenga que ser obligatoriamente activo para integrar los nuevos conceptos en la estructura cognoscitiva del momento. Asimismo, su mentalidad debe ser abierta y universal, crítica e irónica, consigo y con el entorno.

Aprender cómo aprender es algo difícil de teorizar con validez universal, pues el modo de estudiar, dirá Moon "es un descubrimiento personal y solamente puede ser objeto de consejo y de guía por parte del experto".

En su faceta de profesional del estudio, el estudiante debe saber estudiar, ya que en innumerables ocasiones su gran tragedia es la de que nadie le ha enseñado a ello, o sea "nadie le ha preparado o suministrado las herramientas para ejercer su profesión. Es este un problema social en tanto que se trata de un fenómeno colectivo y generalizado en el que se producen escasas excepciones y en cuya solución han de intervenir muchos especialistas y técnicos en distintos ámbitos del saber".?

Por regla general, el cúmulo de conocimientos adquiridos en la Universidad son retenidos por el estudiante en una ínfima parte. Pero en cambio, son los aspectos metodológicos, el dominio de habilidades y el manejo de técnicas apropiadas lo que permanece como piedra angular en la práctica profesional.

Y precisamente la Documentación como disciplina y la aplicación de sus técnicas desempeñan un notorio papel en el proceso de aprendizaje como veremos, puesto que seleccionar, analizar, resumir y organizar información es el núcleo de cualquier actividad en el ámbito intelectual, redundando en la creación de unos métodos racionales y productivos; incluso algunas técnicas documentales, como los sistemas de clasificación o los lenguajes de indización son considerados un buen auxiliar de la memoria para el almacenamiento y recuperación de documentación.

Al decir de Poulsen," "si el estudiante quisiera ser instruido en como subrayar, formular y seleccionar sus objetivos de aprendizaje, buscar las fuentes materiales, planificar y adoptar una actitud crítica respecto a los materiales estudiados asi como valorar los resultados de su estudio se independizaría de los métodos tradicionales de estudio y en una medida saludable del profesor". Y es precisamente aqui donde hay que enclavar el importante protagonismo adquirido por las técnicas documentales en el contexto universitario general y especializado, pues permiten captar la estructura conceptual subyacente, eliminando lo superficial y anecdótico, quedándose con el jugo de lo estudiado.

\section{Las técnicas documentales y su incidencia en el proceso de aprendizaje}

Cualquier esfuerzo investigador o iniciativa docente para ser realizada con éxito,

(8) MOON, J. Same thougth on study skills. Informe, dic., 1976.

(9) COLL VINENT, R.: Introducción a la metodología del estudio. Barcelona, Mitre, 1984, p. 31.

(10) POULSEN, S.G.: The scientific basis of our knowledge about study methods. Copenhague, Institute for educational research, 1969, p. 2. 
necesita la utilización de un determinado método que se adecue en cada paso al objetivo concreto que se persigue y permita una racionalización del esfuerzo intelectual. Además, el sujeto receptor o estudiante deberá emplear un conjunto de elementos y téenicas de trabajo, que contribuyan a conformar su propia dinámica de adquisición y comunicación de saberes.

En general, el recorrido que realiza el estudiante en cualquier proceso de aprendizaje, se asemeja bastante al de las técnicas documentales, a saber: recogida de información; rigurosa selección de la misma; análisis y síntesis; ordenación del material; creación de unos productos documentales coherentes y dispuestos a la difusión... De esta manera, el sujeto del aprendizaje podrá ser ente dinámico en la ejecución de esas técnicas y/o sujeto pasivo, convirtiéndose en usuario de las mismas en el marco de la comunicación docente. Esta comunicación, generalmente podrá adoptar variadas formas, pero centraremos nuestra atención sólo en las que metodológicamente son consideradas más eficaces: la clase magistral, los seminarios, las clases prácticas, los trabajos de curso y el manual.

Habría que preguntarse cómo y en qué medida las técnicas documentales influyen en esos instrumentos de comunicación, qué uso hace de ellas el discente...

La clase magistral, apunta López Yepes" que se "aplica, por lo general, al gran grupo didáctico, estriba en la transmisión de nociones informativas y representa, al mismo tiempo, los primeros estímulos que recibe el educando en cada unidad de contenido". La base de este método es su forma expositiva, y el principal cometido del estudiante, asimilar la máxima cantidad de información. Para ese fin, es recomendable la puesta en práctica de un adecuado procedimiento de toma de notas, o recogida de información, en el que intervendrá al menos una técnica básica, la de resumir, con su marcado esfuerzo de análisis y síntesis necesario para desbrozar la información recibida. Se alternan de este modo el escuchar y el escribir, y como apunta Coll Vinent ${ }^{12}$, "no se pierde nunca, cuando se realiza correctamente, el contacto en cierto modo vivencial entre el emisor y el receptor, inmersos los dos en un proceso de comunicación intelectual y humano profundo en cuanto sea posible. La toma de notas es en ese sentido y sobre todo una técnica para organizar y esquematizar la información que se recibe para que sirva luego a una elaboración ulterior en la que el estudiante aporta sus propias ideas..."

La clase práctica, complemento de la teórica o magistral, conlleva a una fusión del saber y del saber hacer, y en ella el alumno será su sujeto activo, su desarrollo en función de los supuestos prácticos, necesitará una sistematización del problema y la búsqueda de las posibles soluciones, así como la consulta de instrumentos de apoyo (diccionarios, enciclopedias, léxicos...), que aclaren algún concepto o definan con precisión alguna palabra.

De enorme interés también es la ejercitación en la crítica, tanto de las fuentes documentales que van a generar un trabajo científico, como de un documento, dilucidando su autenticidad y credibilidad.

(11) LOPEZ YEPES, J.: El estudio de la documentaciớn: metodología y bibliografia fundamental. Madrid, Tecnos, 1981, p. 61.

(12) COLL VINENT, R.: Op. Cit., p. 64. 
En los seminarios, la enseñanza es cooperativa pues la participación de profesor y alumnos en búsqueda de una meta desconocida beneficia a todos y responde a esa persecución de la verdad que debe presidir cualquier actividad científica. Algunas cuestiones que se plantean al discente una vez conocida la elección del tema de trabajo, estriban en cómo afrontar la recopilación de material -bien sean fuentes publicadas o documentos originales-, cómo organizarlo y proceder a su estudio, qué metodología de trabajo adoptará, qué motivaciones se buscarán durante su transcurso, y cuáles serán las hipotesis y conclusiones a obtener.

Pero será en los trabajos de curso, donde generalmente el estudiante necesite más de la ayuda de unas técnicas documentales por motivos diversos que van desde los planteamientos de la propia elección del tema, la confección del fichas de trabajo, la elaboración de unos índices, la selección de una bibliografía o la estructuración lógica y coherente del esquema de trabajo, que deberá ser provisional y perfeccionable.

La elección del tema deberá hacerla el interesado debidamente, aunque con la ayuda del experto o profesional que guie y dirija esos primeros pasos. En opinión de David Romano, ${ }^{13}$ deberá recaer en temas específicos y concretos más que en macrotemas en los que resulta difícil hacer una profundización seria. En esta tarea intervienen factores subjetivos, como la afición personal, la preparación científica, el conocimiento idiomático...; y factores objetivos, entre los que sobresalen los medios bibliográficos y fuentes documentales de que se dispone, la originalidad de la investigación, etc.

De gran utilidad para el discente en la elaboración de un trabajo es el empleo de un sistema de fichas, que le permitirá múltiples posibilidades: ordenar y clasificar los materiales, intercalar datos, anular otros, cotejarlos... Dentro de los modelos de fichas, los dos más empleados son, por una parte, las bibliográficas, cuyo formato se haya normalizado $(12,5 \times 7,5 \mathrm{~cm})$, y la redacción de la noticia deberá obedecer a un sistema establecido de antemano, ${ }^{14}$ que concrete los elementos a incluir, su distribución, signos de puntuación...; y por otra, las fichas de contenido o lectura como también las denomina Umberto Eco, de tamaño más grande por lo general sirven para señalar una referencia que trate del tema; recoger resúmenes y extractos; anotar citas literales o añadir una serie de observaciones.

Para su correcto uso las fichas deben estar clasificadas (bien sistemática o alfabéticamente o por una fórmula mixta) y ordenadas en ficheros o almacenadas en soportes magnéticos, facilitando así el acceso a la información.

Una vez que se ha fijado el tema e iniciado la búsqueda de las fuentes se puede entonces estructurar el plan de trabajo. Su elaboración es lenta y exige esfuerzos y retoques continuos, en función de la provisionalidad que ha de tener cualquier esquema inicial, pero conlleva enormes ventajas: evita perdida de tiempo, orienta los aspectos del tema que debemos investigar y los va concretando en un orden lógico, y permite una jerarquización de las cuestiones, al distinguir lo esencial de lo accesorio.

(13) ROMANO, D.: Elementos y técnica del trabajo cientifico. Barcelona, Teide, 1983, p. 72.

(14) Nos referimos al apartado nomativo que las técnicas documentales dedican a la confección de las referencias bibliográficas (ISO 690-1975) o a las Reglas de Catalogación españolas. Madrid, Dirección General del Libro y Bibliotecas, 1985. 
En líneas generales, las partes esenciales de un trabajo de investigación podemos resumirlas en:

$1^{2}$ El título, que ha de ser comprensivo, claro y breve.

$2^{2} \mathrm{La}$ introducción o antesala del trabajo, que servirá de base para establecer la génesis y objeto de aquél, sus límites, metodología, bibliografía utilizada, agradecimientos...

$3^{9}$ El cuerpo del trabajo, estructurado en base a capítulos y subcapítulos, convenientemente enumerados para facilitar las referencias internas. Apunta Eco "que una subdivisión muy analítica contribuye a la comprensión lógica del discurso". ${ }^{15}$

$4^{\circ}$ Las conclusiones, deberán ser un buen compendio de los resultados obtenidos.

$5^{9}$ Los apéndices, que complementan o ilustran un trabajo. Podrán ser de naturaleza variada (material textual, gráfico...) y deberán constituir un conjunto coherente.

$6^{2}$ Los indices. Desde el punto de vista de las técnicas documentales podemos decir que es el producto más simple y tradicional de la indización, entendida esta cómo "la técnica de caracterizar un determinado tema de información mediante el recurso de vincularlo coherentemente con unas palabras claves (significativas)". ${ }^{16}$ Por consiguiente el índice es definido como "una serie organizada de puntos de acceso que conducen desde la información conocida por el usuario a una información adicional previamente desconocida"; 17 podemos entreveer pues su enorme utilidad en la búsqueda de información. En cuanto a los tipos de índices, aparte del general de cualquier trabajo, están los alfabéticos, que pueden ser onomástico (antroponímico y toponímico), de materias... Su confección es sencilla, aunque requiere minuciosidad y organización.

$7^{2}$ La bibliografia, es el complemento indispensable de cualquier trabajo serio y su recopilación, registro y organización requiere una metodología mínima: Como la consulta de una serie de obras (diccionarios, enciclopedias, repertorios bibliográficos, revistas especializadas, monografías, y el seguimiento bibliográfico periódico, bien personal o delegado, accediendo a las bases de datos específicas.

Para la confección de la referencia bibliográfica hay distintos criterios, destacando por su talante internacional la norma ISO 690-1975. . $^{18}$

La organización se podrá hacer en ficheros y generalmente siguiendo un criterio temático.

$8^{2}$ Por último habria que mencionar el aparato de notas y citas que completan cualquier trabajo. Pese a que la manera de recogerlas en el texto es múltiple, la más cómoda para el lector es situarla de forma completa, a pie de página con el reenvio al texto, numerándolas correlativamente desde el principio hasta el fin del trabajo.

(15) ECO, U.: Cómo se hace una tésis: técnicas y procedimientos de investigación, estudio y escritura. Barcelona, Gedisa, 1983, p. 145.

(16) SILVA, B.: Origem e evolucao dos descritores. Río de Janeiro, Fundacso Getulio Vargas, 1972, p. 18.

(17) ROWLEY, J.: Abstracting and indexing. London, Clive Bingley, 1982, p. 43.

(18) ORGANIZACION INTERNACIONAL DE NORMALIZACION: ISO 690-1975. Para una mayor información sobre las notas y citas bibliográficas véase: TORRE VILLAR, E. de la: Metodología de la investigación bibliográfica, archivística y documental. Mejico, Me Graw-Hill, 1982. ASTI VERA, A.: Metodología de la investigación. Madrid, Cincel, 1972. 
Finalmente aludiré al manual, que quizá sea el instrumento de comunicación pedagógica más importante para el sujeto del aprendizaje, pues contiene lo sustancial de una disciplina, conformando su esqueleto. La relación del estudiante con el manual es muy diferente a la existente con el docente. En el primer caso dispone de un tiempo ilimitado para aprender y asimilar unos conocimientos limitados; en el segundo, estos son más amplios al ser suministrados progresivamente por el profesor, pero el limitado tiempo de que dispone viene impuesto por la propia planificación docente.

El conocimiento y manejo de las técnicas documentales ayudan al estudiante en el manejo del manual. De entre las más significativas destacaremos:

$1^{\mathfrak{Q}} \mathrm{La}$ técnica de lectura. Requiere unas habilidades y hábitos concretos, necesario muchas veces, para escribir bien. Podemos destacar varias fases en un proceso de lectura, al menos a efectos puramente didácticos y metodológicos: una, la lectura recuperativa, realizada de manera rápida y entrelíneas a fin de detectar las secciones y partes de un trabajo que contienen información significativa, y otra, la lectura analítica creativa, llevada a cabo con profundidad y detenimiento para entresacar $y / o$ asimilar, articular y organizar lo sustancioso.

La manera más práctica de llevar a cabo esta actividad es utilizando el subrayado, método que permitirá al estudiante captar y aislar los conceptos claves en un documento, dejando de lado lo accesorio.

$2^{2}$ Asimismo es también importante la técnica de resumir o transformación condensada que experimenta el contenido de cualquier documento sometido a un análisis y sintesis. El análisis permitirá extraer las frases significativas al igual que las formulaciones con más contenido, disociando lo sustancial de lo secundario, y la síntesis, tratará de recomponer lo que el análisis descompuso, pero no yuxtaponiendo los elementos aislados, sino dándoles una unidad y sentido nuevos.

El resultado de esta técnica se plasmará en la confección del resumen (abstract), instrumento válido tanto para quien lo elabora como para quien lo utiliza, pues sirve de anticipo del documento original y contribuye a la actualización de conocimientos.

\section{Puntualizaciones finales}

En resumidas cuentas la problemática del aprendizaje podría sintetizarse en los siguientes puntos:

- Por un lado, es una labor universal que afecta a todos los sectores de la actividad humana, pudiendo decirse que es consustancial a la persona. Además, y centrados ya en el mundo de la ciencia, se trata de un ejercicio muy importante, probablemente el de mayor relevancia, sobre todo en lo que al estudiante o profesional del estudio se refiere.

- Por otra parte debemos tener muy en cuenta que desgraciada y paradójicamente, en bastantes ocasiones este profesional del aprendizaje no sabe estudiar, como se demuestra a través de los más o menos afortunados sistemas de evaluación pedagógica que, al margen de su calidad, confirman unánimemente el fracaso de los métodos empleados hasta la fecha.

- No resulta difícil concluir afirmando que el aprendizaje es tarea necesitada de 
una investigación específica que le conduzca a las más apropiadas técnicas objetivas, ya que por el momento no se dispone de valores universales pedagógicamente contrastados.

Por lo que a la Documentación, y más concretamente a las técnicas documentales se refiere, debemos hacer las siguientes puntualizaciones:

- No se puede ignorar que las actividades documentales nacen con una expresa vocación instrumental, como ayuda al científico en las tareas docente e investigadora. Su concurso es ineludible en la denominada "selva documental" para desbrozar la creciente invasión informativa.

- La participación de estas técnicas en los procesos de aprendizaje mejorará sin duda los rendimientos, optimizando el esfuerzo intelectual del estudiante, objetivo este último que justifica cualquier iniciativa pedagógica.

- Por consiguiente, concluiremos afirmando que sería muy aconsejable, e incluso necesario, la introducción al estudiante en el conocimiento y la práctica de estas técnicas documentales, cuya presencia institucional a través de los planes de estudio reformaría positivamente los vigentes modelos de relación pedagógica. 